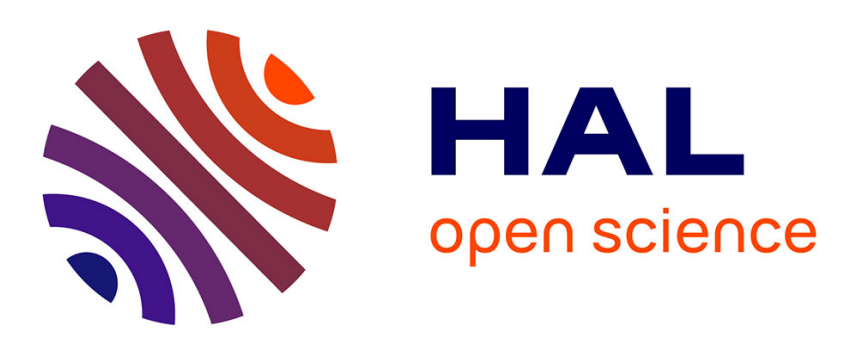

\title{
Diglycolamide-functionalized resorcinarene for rare earths extraction
}

\author{
Moheddine Wehbie, Guilhem Arrachart, Iyad Karame, Leila Ghannam, S \\ Pellet-Rostaing
}

\section{- To cite this version:}

Moheddine Wehbie, Guilhem Arrachart, Iyad Karame, Leila Ghannam, S Pellet-Rostaing. Diglycolamide-functionalized resorcinarene for rare earths extraction. New Journal of Chemistry, 2016, 40 (11), pp.9344-9351. 10.1039/c6nj02195f . hal-02062520

\section{HAL Id: hal-02062520 \\ https://hal.science/hal-02062520}

Submitted on 26 Oct 2021

HAL is a multi-disciplinary open access archive for the deposit and dissemination of scientific research documents, whether they are published or not. The documents may come from teaching and research institutions in France or abroad, or from public or private research centers.
L'archive ouverte pluridisciplinaire HAL, est destinée au dépôt et à la diffusion de documents scientifiques de niveau recherche, publiés ou non, émanant des établissements d'enseignement et de recherche français ou étrangers, des laboratoires publics ou privés. 


\title{
Diglycolamide-Functionalized Resorcinarene for Rare Earths Extraction.
}

\author{
Moheddine Wehbie, ${ }^{a, b}$ Guilhem Arrachart, ${ }^{a}$ Iyad Karamé, ${ }^{b}$ Leila Ghannam, ${ }^{b}$ and Stéphane Pellet-Rostaing ${ }^{a *}$ \\ a Institut de Chimie Séparative de Marcoule, ICSM, UMR5257-CEA/CNRS/UM2/ENSCM Site de Marcoule, Bâtiment 426, BP 17171, F-30207 Bagnols sur Cèze \\ Cedex, France. E-mail: stephane.pellet-rostaing@cea.fr \\ ${ }^{b}$ Laboratory of Catalysis, Coordination and OrganoMetallic (LCOM), Department of Chemistry, Lebanese University, Faculty of Sciences I, Hadath, Lebanon. E- \\ mail: iyad.karameh@ul.edu.lb
}

A C-methylcalix(4)methylresorcinarene-DODGA ligand, derived from calix[4]methylresorcinarene functionalized with four diglycolamide (DGA) binding units was synthesized and characterized by NMR and MS. The ligand was investigated toward the extraction of rare earth elements (REEs) from nitric acid solution. High sensitivity was observed particularly toward heavy rare earth elements. Acidity effects as well as the concentration of the extractant were evaluated on the extraction and separation efficiencies. The results showed that the distribution coefficient values increase with an increase in nitric acid concentration in the range of 0.1 to $5 \mathrm{~mol} / \mathrm{L}$. Slope analysis method and spectrophotometric titrations showed a clear complexation of the REEs with the ligand. An extraction mechanism is proposed from the estimation of the thermodynamic parameters $(\Delta \mathrm{H}, \Delta \mathrm{S}$, and $\Delta \mathrm{G})$. The extraction and stripping of REEs from a simulated leaching solution of a $\mathrm{Nd} / \mathrm{Fe} / \mathrm{B} / \mathrm{Dy}$ magnet have been studied.

\section{Introduction}

The separation and purification of the rare-earth elements (REEs) which includes the lanthanides has gained considerable importance for many reasons.

The separation and partitioning of the minor actinides (Am) from the lanthanides ( $\mathrm{Ln}$ ) is a crucial step in order to improve the global sustainability of nuclear energy and to contribute to the successful deployment of the currently envisioned advanced new generation closed nuclear fuel cycles. ${ }^{1-4}$

In addition, REEs are essential in many and relevant applications such as high technology (cell phones, LCD panels, disk drives...), renewable energy (wind turbines), etc... As such they have become a political buzzword due to their economic importance and high supply potential. Separation and recovery of these elements is at the forefront of priorities for industrial countries (Report on Critical Raw Materials for the EU (May 2014)).

Extractants such as CMPO (carbamoylmethylphosphine oxide), TRPO (tri-alkylphosphine oxide), DIDPA (diiosodecylphosphoric acid), are well known for the extraction of trivalent actinides and lanthanides from moderate acidic medium. However due to the presence of phosphorous atoms in such ligands they cannot be completely incinerated and the degraded products produce additional wastes, a main drawback which is not present for malonamide based extractants. Unlike the other reagents in use for Ln-An separation, diglycolamides (DGA) and malonamides are made up of $\mathrm{C}, \mathrm{H}, \mathrm{N}$, and $\mathrm{O}$ atoms, and thus they can be incinerated completely to a gaseous product after utilization. ${ }^{5-8}$

In the early 1990s, Stephan et $a^{19}$ reported the extraction of metal ions using multidentate DGA. Sasaki and Choppin ${ }^{10}$ recognized that these ligands are particularly suitable for extracting actinides and lanthanides and are more efficient than malonamides. The extractability of $\operatorname{Ln}(\mathrm{III})$ follows the sequence diglycolamide > malonamide suggesting that the introduction of one ether oxygen is effective for the $\mathrm{Ln}(\mathrm{III})$ intra-group separation. ${ }^{11}$ Therefore mutlidentate DGA are the appropriate extractants for trivalent actinides and lanthanides. However, as for malonamides diglycolamides can form a third phase when contacted with moderate concentrations of nitric acid. The presence of spacers of alkyl groups on the amide nitrogen atoms and /or the use of a phase modifier can be a solution in order to avoid this drawback. ${ }^{12,13}$

Based on the performances of such ligand for lanthanide extraction, we investigated the possibility to introduce such DGA units on a resorcinarene platform for the specific extraction of lanthanides.

In 2012, M. Iqbal et al reported the preorganization of multidentate DGA ligands grafted on calix(4)arene platform. ${ }^{12}$ They showed that the extraction efficiency of calix(4)arene diglycolamide is much higher than the DGA ligand itself and the efficiency increases with the increase of the number of DGA units. Even the alkyl groups bounded to the amide nitrogen atoms close to the calixarene platform would force the amide oxygen atoms inward to prevent the steric hindrance, and consequently give rise to higher extraction efficiency. ${ }^{12}$ Therefore the preorganization of the DGA ligating sites on a molecular platform appears as a very attractive approach for the liquid-liquid extraction of REEs.

Among different supramolecular architectures, C-methylcalix(4)methylresorcinarene provides an excellent preorganized platform for the coordination of host systems due to its conformational rigidity, which is assured by the methylene bridgings between the hydroxyl groups of two neighboring phenyl rings. Functionalization could easily be completed on both rims making the platform a focus of interest for a wide range of applications: host molecules, ${ }^{14-15}$ components in liquid crystals ${ }^{16}$, photoresists ${ }^{17}$, HPLC 
stationary phase ${ }^{18}$, self-assembled capsules, ${ }^{19}$ surfactants and potential sensor applications ${ }^{20}$, antibacterial. ${ }^{21}$ The potential of this type of platform has also been demonstrated for the extraction of europium thanks to the steric preorganization of four (carbamoylmethyl)phosphonate or -phosphine oxide CMP(O) ligands on a resorcinarene cavitand. ${ }^{22,23}$

We recently, synthesized a tetramethylcavitand functionalized at the upper rim with four 1,2,3-triazole-DGA binding units containing n-octyl groups which shown promising extraction performances for REEs extraction. ${ }^{24}$

In the current contribution, we present here the synthesis and characterization of C-methylcalix(4)methylresorcinarene III, denoted by CR4-DODGA (Figure 1). In the presented work, the four diglycolamide moieties of the tetrafunctionalized resorcinarene were directly introduced thanks to an amide coupling reaction. Thereby, no triazoles groups are involved in the attachments of the DGA ligating sites to the cavitand plateform. The extraction capacity and behavior of this macro-ligand was studied toward REEs extraction. The extraction mechanism is described and the thermodynamic parameters are also discussed.

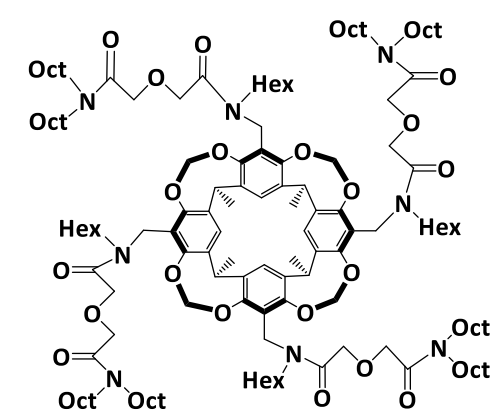

Figure 1: Structural formula of CR4-DODGA (for clarity the bond angles around the resorsinarene do not represent the actual angles of the ligand).

\section{Results and discussion}

\subsection{Synthesis}

Cavitand III was synthesized in two steps from (bromoethyl)cavitand I according to scheme 1 . The cavitand I was prepared in two steps according to the procedures already described. ${ }^{25,26}$ Cavitand II was synthesized directly from cavitand I by a direct $\mathrm{N}$ alkylation with hexyl amine, in which I was dissolved in an excess amount of hexyl amine at room temperature and the reaction took place instantly with quantitative yield. Finally, the cavitand III was obtained in $50 \%$ yield by amide coupling of cavitand II with DODGA $^{27}$ using DCC as coupling agent in the presence of HOBt.

The formation of compound III was confirmed by the appearance of new signals in the ${ }^{1} \mathrm{H}-\mathrm{NMR}$ and ${ }^{13} \mathrm{C}-\mathrm{NMR}$ spectra correspond to the hexyl groups in addition to the up field shift of the $\mathrm{Ar}-\mathrm{CH}_{2}-\mathrm{N}$ in the ${ }^{1} \mathrm{H}-\mathrm{NMR}$ spectrum from 4.42 to $3.58 \mathrm{ppm}$. Furthermore, the cavitand III was characterized by the appearance of two resonance signals in the ${ }^{13} \mathrm{C}-\mathrm{NMR}$ at 68.8 and $69.1 \mathrm{ppm}$ which corresponds to the $\mathrm{CH}_{2}$ methylene groups of the DGA arms in addition to another peak at 168 ppm correspond to the amide carbonyl groups. The structure of the cavitand III was confirmed by ${ }^{1} \mathrm{H}-\mathrm{NMR},{ }^{13} \mathrm{C}-\mathrm{NMR}, \mathrm{DEPT} 135, \mathrm{COSY}$, and HSQC in addition to the high resolution mass spectroscopy (see supporting information).

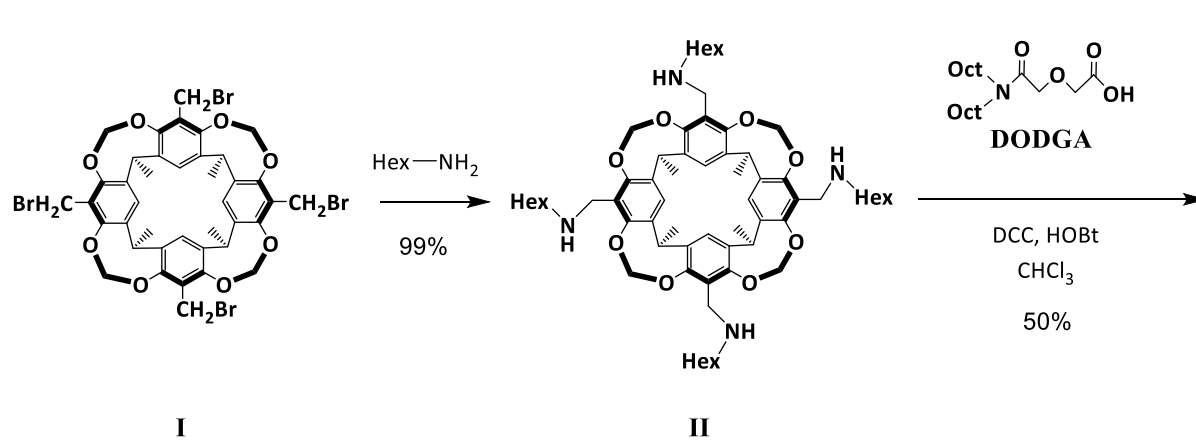

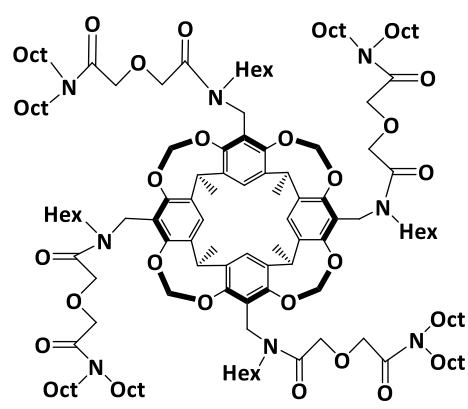

III (CR4-DODGA) 


\subsection{Liquid-Liquid Extraction}

\subsubsection{Extraction experiments}

Solvent extraction studies were carried out using a solution of CR4-DODGA in a mixture of toluene and iso-octanol (9/1, v/v). The extraction profile was established for La, and Eu as light rare earth elements (LREE) and Yb as heavy rare earth element (HREE). The solvent extraction data of $\mathrm{La}(\mathrm{III}), \mathrm{Eu}(\mathrm{III})$ and $\mathrm{Yb}(\mathrm{III})$ from $5 \mathrm{M}$ HNO3 using various concentration of CR4-DODGA ligand are summarized in Table 1. The metal to ligand ratios ( $M: L)$ were varied from (1:1) up to (1:15). No significant extraction of LREE was observed at low concentration of extractant, however their extraction performances were significantly increased with the increase of the ligand concentration. The CR4-DODGA ligand reached much higher D values for $\mathrm{Yb}$ than for La and Eu at comparable conditions. Distribution ratios of $\mathrm{Yb}$ are significantly higher than those of Eu and La.

Table 1: Extraction data of individual $\operatorname{Ln}(\mathrm{III})(0.66 \mathrm{mM})$ by CR4-DODGA $(0.63$ to $10 \mathrm{mM})$ in $10 \%$ iso-octanol/toluene from $5 \mathrm{M}$ nitric acid solution at $25^{\circ} \mathrm{C}$

\begin{tabular}{cccc}
\hline [CR4-DODGA] & D(La) & D(Eu) & D(Yb) \\
\hline $\mathbf{0 . 6 3}$ & 0.2 & 0.9 & 4 \\
$\mathbf{1 . 2 5}$ & 0.35 & 1 & 13.1 \\
$\mathbf{2 . 5 0}$ & 0.6 & 2.9 & 36.7 \\
$\mathbf{5 . 0 0}$ & 1.1 & 8.9 & 111 \\
$\mathbf{1 0 . 0 0}$ & 2.3 & 32.8 & 268 \\
\hline
\end{tabular}

\subsubsection{Effect of nitric acid concentration}

Figure 2 represents the distributions and selectivity results obtained for the mutual extraction of $\mathrm{La}^{3+}$, Eu ${ }^{3+}$, and $\mathrm{Yb}^{3+}$ with $\mathrm{CR}^{3-}$ DODGA ligand while varying the concentration of nitric acid from 0.1 to $5 \mathrm{M}$. The mutual extraction data of lanthanide cations (La ${ }^{3+}$, $\mathrm{Eu}^{3+}$, and $\mathrm{Yb}^{3+}$ ) as function of the acidity are summarized in Table S1 (see supporting information).

The presented data shows clearly the dependence of the distribution values and the selectivity factors on the concentration of the feed nitric acid. The result is in good agreement with the behaviour observed in liquid-liquid extraction systems with neutral ligands (solvating agents). Generally an increase in the feed nitric acid concentration leads to an increase in the distribution ratio values. In this study, extraction of REEs increased with an increase in the concentration of nitric acid up to $5 \mathrm{M}$ (Figure 2). The same trend was observed for the selectivity factors, in which the $S_{(\mathrm{Yb} / \mathrm{La})}$ and $\mathrm{S}_{(\mathrm{Yb} / \mathrm{Eu})}$ increased from about 0.8 to 83 and from about 1 to 14 respectively. The ligand showed a preferential extraction of HREE (Yb) in regard to the LREE (Eu and La). This behaviour is even more significant when the ligand concentration is increased (see Table S2 in the supporting information).

Interestingly, the trend in extraction performance ( $\mathrm{Yb}>\mathrm{Eu}>>>\mathrm{La}$ ) seems to be proportional to the lanthanide contraction and related to the charge density of the metal ion showing a higher selectivity for the heavy rare earth elements (HREEs). Based on the HSAB theory, O-donors extractants including DGA are usually considered as hard ligands 28 , therefore it is admit that they strongly bind cations with higher positive charge densities suggesting that the HREE-DGA complexes are more stable than the LREE-DGA complexes. Otherwise, the necessary energy required to dehydrate the REEs is improved with increasing atomic number and decreasing ionic radii. ${ }^{29}$ Thereby the selectivity for HREE suggest that the coordination ability of CR4-DODGA toward REEs is predominant over their dehydration energies.

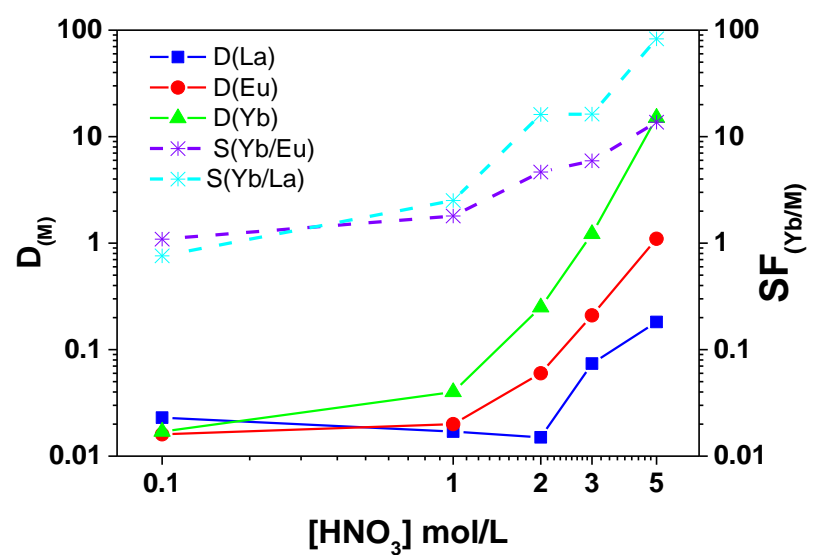

Figure 2: Effect of nitric acid concentration on the Distribution ratios and the selectivity factors of La(III), Eu(III), and Yb(III); org. phase: $1 \mathrm{mmol} / \mathrm{L} \mathrm{CR4-DODGA} \mathrm{in} 90 \%$ toluene/10\% iso-octanol (v/v); aq. phase: $1 \mathrm{mmol} / \mathrm{L} \operatorname{Ln}\left(\mathrm{NO}_{3}\right)_{3}$ in $\mathrm{HNO}_{3}$, (equimolar concentrations of metals $=0.33 \mathrm{mmol} / \mathrm{L}$ ). Metal to ligand ratios $(\mathrm{M}: \mathrm{L})=1: 3$ 
However, other factors such as the geometry of the coordination site and the hydrophobicity of the extracted complexes have to be considered. ${ }^{11}$ The rigidity of the macrocycle has a dramatic influence on the selectivity and complexation of metal ions which largely depends on the ionic radius of the metal.

By comparing the current result with the previous work ${ }^{24}$, where triazoles linkers to the DGA units and the cavitand plateform, it was found that for two similar experiments of the two cavitands for the mutual extraction of lanthanide $\mathrm{Cations}\left(\mathrm{La}^{3+}, \mathrm{Eu}^{3+}\right.$, and $\mathrm{Yb}^{3+}$ ) under the same conditions, the present work is more effective for the extraction of the REEs but less suitable for the separation LREE / HREE with weaker separation factors than the previous work (see Table S3 in the supporting information). The influence of the triazole rings on the extraction performance is being evaluated and will be reported in due course.

\subsubsection{Effect of extractant concentration}

CR4-DODGA is considered as a neutral complex extractant which forms complexes with the trivalent lanthanides through a mechanism which can be described in the following equation. ${ }^{8}$

$$
\mathrm{M}^{3+}+3 \mathrm{NO}_{3}^{-}+\bar{L} \stackrel{\mathrm{K}_{\mathrm{ex}}}{\rightleftharpoons} \overline{M\left(\mathrm{NO}_{3}\right)_{3} \cdot L}
$$

where $M$ represents the REEs, $\bar{L}$ represents the neutral extractant (CR4-DODGA), and $\overline{M\left(\mathrm{NO}_{3}\right)_{3} \cdot L}$ represents the metalextractant complex in the organic phase. The overbar refers to species in the organic phase and the absence of the overbar denotes aqueous species.

Given that CR4-DODGA extracts REEs mainly by a solvation mechanism, the extracted REEs must neutralized by the $\mathrm{NO}_{3}{ }^{-} \mathrm{Counter}^{-}$ ions. Acid extraction by the neutral compound was considered negligible. ${ }^{29}$

To determine the stoichiometry of complexation $n$, the distribution ratios for the metal extraction at constant acidity were plotted as a function of extractant concentrations.

The $D$ values increased with increasing ligand concentrations; this indicates that the CR4-DODGA is directly participating in complex formation. The slope analysis method (Figure 3) was used to confirm the metal to ligand ratio, straight lines with slopes of 1.137, 1.501 and 0.839 was found for $\mathrm{Yb}(\mathrm{III}), \mathrm{Eu}(\mathrm{III})$ and $\mathrm{La}(\mathrm{III})$, respectively.

This suggests that the metal:ligand extraction stoichiometry for Ln is mainly $1: 1$, which is consistent with the solvent extraction studies reported in the literature. ${ }^{30}$

Electrospray ionization mass spectrometry (ESI-MS) was used to obtain information about the stoichiometry of complexes formed with $\mathrm{Yb}(\mathrm{III})$. Species were identified by comparison to the calculated isotopic pattern as shown in supporting information (see Figure S2 and S3 in the supporting information). These observations indicate that in the gas phase, mainly a 1:1 stoichiometry is considered. Also the ESI-MS analysis of two complexes prepared from a 1:1 and 1:2 metal/ligand molar ratio provide similar spectra corresponding to a 1:1 complexation.

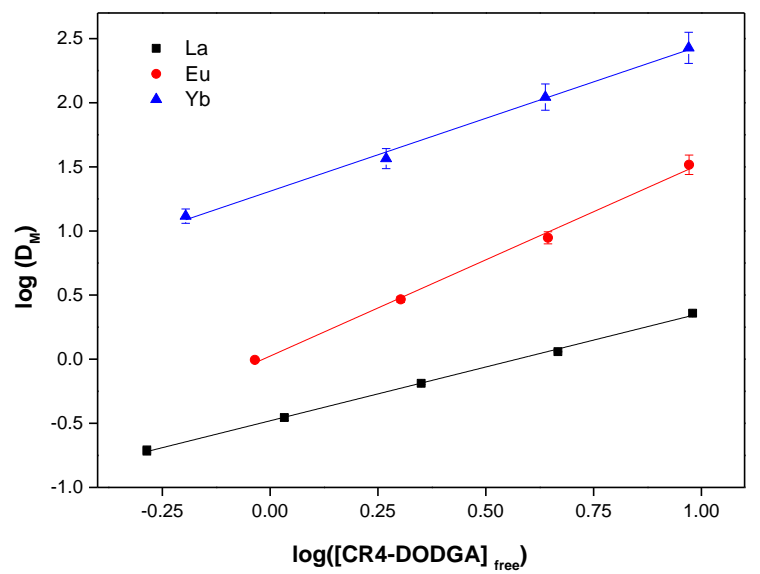

Figure 3: Logarithm of the distribution coefficient of REEs as a function of [CR4-DODGA]free; Org. phase: 0.625-10 mmol/L CR4-DODGA in 90\% toluene/10\% iso-octanol (v/v); Aq. phase: $1 \mathrm{mmol} / \mathrm{L} \operatorname{Ln}\left(\mathrm{NO}_{3}\right)_{3}$ in $5 \mathrm{~mol} / \mathrm{L} \mathrm{HNO}_{3},(\mathrm{~A} / \mathrm{O}=1)$.

$\log (D$ La $)=f(\log [C R 4-D O D G A] f r e e): y=0.839( \pm 0.016) x-0.480( \pm 0.009) ; R^{2}=0.998 . \log (D E u)=f(\log [C R 4-D O D G A] f r e e): y=1.501( \pm 0.058) x+0.024( \pm 0.035) ; R^{2}=0.997 . \log (D Y b)=f$ $\left(\log \left[\right.\right.$ CR4-DODGA]free): $y=1.137( \pm 0.049) x+1.310( \pm 0.030) ; R^{2}=0.996$. 
Therefore the extraction constant, $\mathrm{K}_{\mathrm{ex}}$, can be represented as:

$$
K_{\text {ex }}=\frac{\overline{\left[M\left(\mathrm{NO}_{3}\right)_{3} \cdot L\right]}}{\left[\mathrm{M}^{3+}\right] \times\left[\mathrm{NO}_{3}^{-}\right]^{3} \times \overline{[L]_{\text {free }}}}
$$

The distribution constant is represented in terms of stability constant, $\beta_{i}$, for nitrate complexes of $M($ III) as described in the following equation:

$$
D_{M}=\frac{\overline{\left[M\left(\mathrm{NO}_{3}\right)_{3} \cdot L\right]}}{\left[M^{3+}\right]\left(1+\sum \beta_{i}\left[\mathrm{NO}_{3}^{-}\right]^{i}\right)}
$$

By substituting the value of $\overline{\left[M\left(\mathrm{NO}_{3}\right)_{3} \cdot L\right]} /\left[\mathrm{M}^{3+}\right]$ from eq. (3) into equation (2) the constant of extraction can be expressed as:

$$
K_{e x}=\frac{D_{M}\left(1+\sum \beta_{i}\left[N O_{3}^{-}\right]^{i}\right)}{\left[\mathrm{NO}_{3}^{-}\right]^{3} \times \overline{[L]_{\text {free }}}}
$$

The $\beta_{i}$ values for the $\mathrm{NO}_{3}^{-}$complexation of $\mathrm{La}(\mathrm{III})$, and Eu(III) were obtained from the literature as $\left(\beta_{1}=1.29, \beta_{2}=0.36\right.$ for $\left.\mathrm{La}\right)$ and $\left(\beta_{1}=1.86, \beta_{2}=0.43\right.$ for $\left.\mathrm{Eu}\right)$ at ionic strength of 5.0. ${ }^{31} \beta_{1}$ of $\mathrm{Yb}$ was estimated between 0 and 0.25 due to the lack of information about $\mathrm{Yb}(\mathrm{III})$, and the corresponding LogKex values are provided in range values corresponding to the estimated values of $\beta_{1}, 0$ and 0.25 (Table 2). From the distribution data, the apparent extraction equilibrium constants can be estimated. The average values

\begin{tabular}{|c|c|c|c|c|c|c|c|}
\hline \multicolumn{2}{|c|}{ [Ligand] mM } & 0.625 & 1.25 & 2.5 & 5.00 & 10 & $\begin{array}{c}\text { Av. } \\
\log _{(\text {(Kex) }}\end{array}$ \\
\hline \multirow[t]{2}{*}{ La } & D & 0.2 & 0.35 & 0.6 & 1.1 & 2.3 & \\
\hline & $\log _{(\text {Kex })}$ & 1.69 & 1.63 & 1.58 & 1.51 & 1.49 & 1.60 \\
\hline \multirow[t]{2}{*}{ Eu } & D & 0.9 & 1 & 2.9 & 8.9 & 32.8 & \\
\hline & $\log _{(\text {Kex })}$ & 2.71 & 2.26 & 2.39 & 2.53 & 2.77 & 2.47 \\
\hline \multirow[t]{3}{*}{$\mathrm{Yb}$} & D & 4. & 13.1 & 36.7 & 111 & 268 & \\
\hline & $\log _{(\text {Kex })} \quad \beta=0$ & 2.53 & 2.21 & 2.19 & 2.31 & 2.36 & 2.66 \\
\hline & $\beta=0.25$ & 2.88 & 2.57 & 2.55 & 2.66 & 2.71 & 2.49 \\
\hline
\end{tabular}
of logKex for $\mathrm{La}(\mathrm{III})$, Eu(III) and $\mathrm{Yb}(\mathrm{III})$ with the ligand are 1.6, 2.47 and 2.66-2.49, respectively (Table 2).

Table 2: Extraction equilibrium constants for $\mathrm{La}(\mathrm{III}), \mathrm{Eu}(\mathrm{III})$, and $\mathrm{Yb}(\mathrm{III})$ at $298 \mathrm{~K}$.

Organic phase: $0.625-10 \mathrm{mmol} / \mathrm{L} \mathrm{CR4-DODGA}$ in 90\% toluene/10\% iso-octanol (v/v); Aq. phase: $1 \mathrm{mmol} / \mathrm{L} \mathrm{Ln}\left(\mathrm{NO}_{3}\right)_{3}$ in $5 \mathrm{~mol} / \mathrm{L} \mathrm{HNO}$.

\subsubsection{Effect of temperature}

The effect of temperature on the extraction of lanthanides from $5 \mathrm{M} \mathrm{HNO}_{3}$ by $1 \mathrm{mM}$ of CR4-DODGA into toluene/iso-decanol 10\% was studied at a temperature range varied from 25 to $45^{\circ} \mathrm{C}$. The distribution ratio for $\mathrm{Ln}(\mathrm{III})$ was found to decrease with increasing temperature, indicating the extraction process to be exothermic (Figure 4). The change in the enthalpy $(\Delta \mathrm{H}) \mathrm{can}$ be calculated using the Van't Hoff relationship:

$$
\log K_{e x}=-\frac{\Delta \mathrm{H}}{2.303 R} \cdot \frac{1}{T}+\frac{\Delta \mathrm{S}}{2.303 R}
$$

where $R$ is the gas constant.

From the plot of $\log _{\text {ex }}$ versus $1 / T$, straight lines were obtained as shown in Figure 4 . The $\Delta H$ was determined from the slopes of the straight lines (1.45 for $\mathrm{La}(\mathrm{III}), 0.93$ for $\mathrm{Eu}(\mathrm{III})$, and 1.03 for $\mathrm{Yb}(\mathrm{III})$ ), while the entropy was estimated in a first approximation from the intercept values (-3.6 for $\mathrm{La}(\mathrm{III}),-0.96$ for $\mathrm{Eu}(\mathrm{III})$, and -1.1 for $\mathrm{Yb}(\mathrm{III})$ ). In addition the free energy change, $\Delta \mathrm{G}$, for the extraction at $298 \mathrm{~K}$ was obtained from the Gibbs's Helmholtz equation.

$$
\Delta \mathrm{G}=\Delta \mathrm{H}-\mathrm{T} \Delta \mathrm{S}=-2.303 \mathrm{RT} \log \mathrm{K}
$$

The thermodynamic parameters, $\Delta \mathrm{H}, \Delta \mathrm{S}$, and $\Delta \mathrm{G}$ for the extraction of CR4-DODGA are summarized in Table 3. The results indicate that the extraction mechanism is different for the REEs regarding the entropy and enthalpy factors that can affect the extent of the metal ion extraction, for Eu and $\mathrm{Yb}$ the processes are entropy driven.

The overall enthalpy change depends on several contributing factors, such as, (i) dehydration of metal ions $\left(\Delta \mathrm{H}_{1}\right)$, (ii) formation of neutral extracted species $\left(\Delta \mathrm{H}_{2}\right)$, and (iii) dissolution of metal complex in the organic phase $\left(\Delta \mathrm{H}_{3}\right)$. 
The negative $\Delta \mathrm{H}$ values suggests that the complexations between $\mathrm{Ln}(\mathrm{III})$ metal nitrate species and the neutral extractant molecule are exothermic (Table 3).

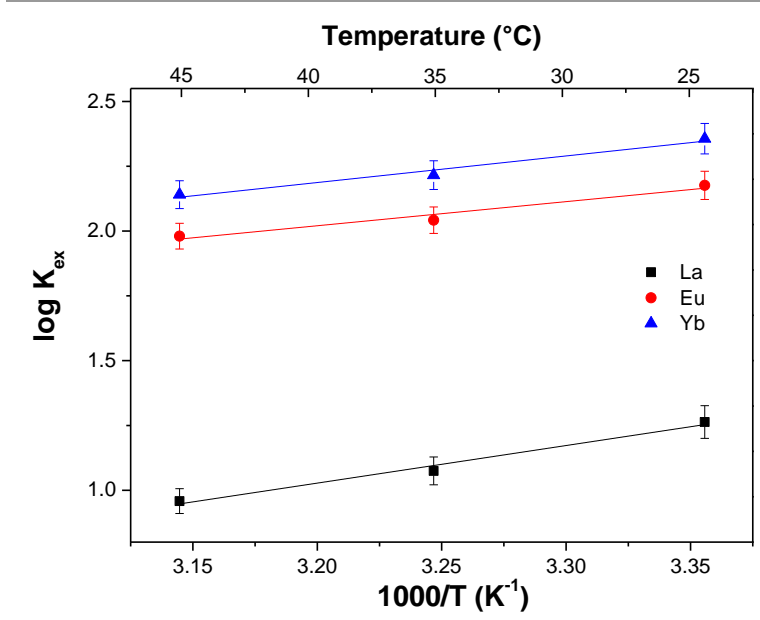

Figure 4: Effect of temperature on the apparent extraction equilibrium constants logK $\mathrm{ex}$. Org. phase: $1 \mathrm{mmol} / \mathrm{L}$ CR4-DODGA in $90 \%$ toluene/10\% iso-octanol (v/v); Aq. phase: $1 \mathrm{mmol} / \mathrm{L}$ $\operatorname{Ln}\left(\mathrm{NO}_{3}\right)_{3}$. in $5 \mathrm{~mol} / \mathrm{L} \mathrm{HNO}_{3}$.

$\log ($ Kex La $)=f(1000 / T): y=1.450( \pm 0.169) x-3.612( \pm 0.552) ; R^{2}=0.986$ $\log (\mathrm{Kex} E u)=f(1000 / T): y=0.930( \pm 0.182) x-0.957( \pm 0.559) ; R^{2}=0.963$ $\log (\operatorname{Kex} Y b)=f(1000 / T): y=1.026( \pm 0.159) x-1.096( \pm 0.518) ; R^{2}=0.976$

Table 3 : Thermodynamic parameters $(\Delta \mathrm{H}, \Delta \mathrm{S}$, and $\Delta \mathrm{G})$ for the extraction of $\mathrm{La}(\mathrm{III}), \mathrm{Eu}(\mathrm{III})$ and $\mathrm{Yb}(\mathrm{III})$ at $298 \mathrm{~K}$.

\begin{tabular}{|c|c|c|c|c|c|}
\hline system & slope & Intercept & $\begin{array}{c}\Delta \mathrm{H} \\
\left(\mathrm{kJ} \mathrm{mol}^{-1}\right)\end{array}$ & $\begin{array}{c}\Delta S \\
\left(\mathrm{~J} \mathrm{~K}^{-1} \mathrm{~mol}^{-1}\right)\end{array}$ & $\begin{array}{c}\Delta \mathrm{G} \\
\left(\mathrm{kJ} \mathrm{mol} \mathrm{mo}^{-1}\right)\end{array}$ \\
\hline LaL & 1.45 & -3.61 & -27.76 & -69.17 & -7.15 \\
\hline $\mathrm{EuL}_{2}$ & 0.93 & -0.96 & -17.81 & -18.32 & -12.35 \\
\hline YbL2 & 1.03 & -1.10 & -19.64 & -20.98 & -13.39 \\
\hline
\end{tabular}

Org. phase: $1 \mathrm{mmol} / \mathrm{L}$ CR4-DODGA in $90 \%$ toluene/10\% iso-octanol (v/v); Aq. phase: $1 \mathrm{mmol} / \mathrm{L} \mathrm{Ln}\left(\mathrm{NO}_{3}\right)_{3}$. in $5 \mathrm{~mol} / \mathrm{L} \mathrm{HNO}$.

Negative entropy changes $(-\Delta S)$, suggest the presence of a few water molecules in the hydrated $\operatorname{Ln}(I I I)$.

The change in the Gibbs free energy $(-\Delta G)$ follows the order: $\Delta G(Y b)>\Delta G(E u)>\Delta G(L a)$ which is the same order of extraction. The negative value of $\Delta G$ at room temperature indicates that the extraction reactions are spontaneous. More negative $\Delta G$ value for $\mathrm{Yb}$ (III) shows that the formation of monosolvated $\mathrm{Yb}$ (III)-CR4-DODGA complex is thermodynamically more favored as compared to the monosolvated complexes of $\mathrm{Eu}(\mathrm{III})$ and $\mathrm{La}(\mathrm{III})$ respectively. ${ }^{32}$

\subsection{Spectrophotometric studies}

FT-IR spectroscopy was used to investigate the interactions between the ligand and europium in organic solvent. Figure 5 shows a representative IR titration of the ligand with $\mathrm{Eu}\left(\mathrm{NO}_{3}\right)_{3} .5 \mathrm{H}_{2} \mathrm{O}$ in ethanol. $\mathrm{As} \mathrm{Eu}(\mathrm{III})$ was added to the ligand solution, the intensity of the band of the CR4-DODGA at $1636 \mathrm{~cm}^{-1}$ which corresponds to the amide groups $(\mathrm{C}=0)$, decreased with a simultaneous increase of a band at $1610 \mathrm{~cm}^{-1}$. The shift $\mathrm{v}_{\mathrm{C}=\mathrm{O}}\left(1636\right.$ to $\left.1610 \mathrm{~cm}^{-1}\right)$ upon the addition of Eu(III) indicates that the amide groups of CR4DODGA are involved in the extraction of the metal cation. It is interesting to note that from 1:1 metal/ligand ratio the $1636 \mathrm{~cm}^{-1}$ carbonyl band corresponding to the free ligand disappears completely. 


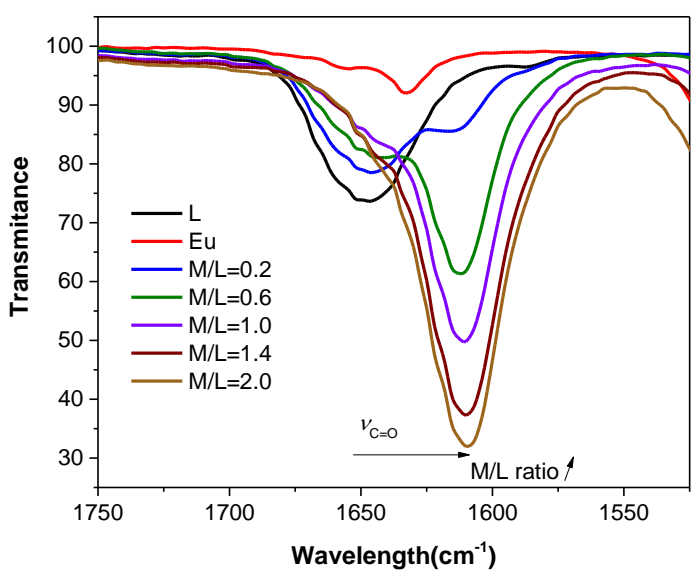

Figure 5: IR titration of CR4-DODGA (L) with $E u(I I I)(M)$ in ethanol for different $M / L$ ratios.

In addition UV-vis titration has been performed, Figure 6 shows a representative spectrophotometric titration of the ligand with $\mathrm{Eu}^{3+}$ in ethanol. A strong absorption band between 265 and $290 \mathrm{~nm}$ is observed. Upon increasing the metal/ligand ratio, a significant increase in the absorbance has been observed at $275 \mathrm{~nm}$ without changes in the position of the band as already observed in the literature. ${ }^{28}$ Interestingly, from a 1:1 metal/ligand ratio the absorbance intensity value seems to be constant which is consistent with the stoichiometry proposed from the previous experiments.

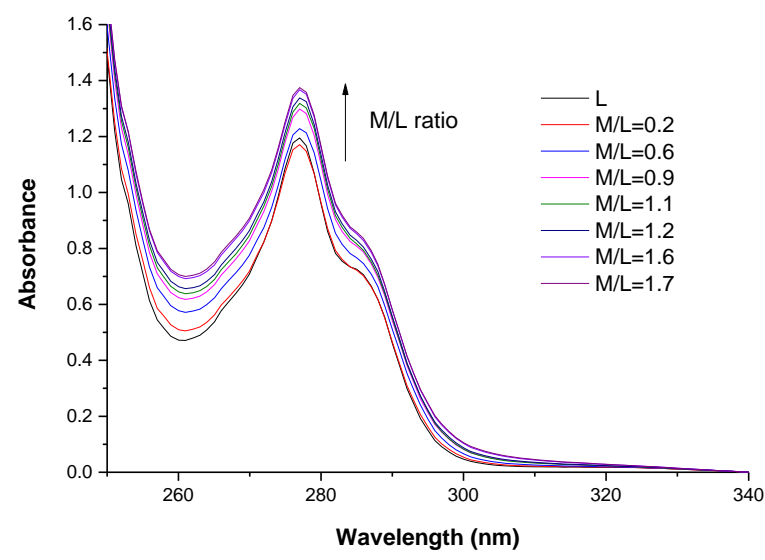

Figure 6: UV-vis titration of CR4-DODGA (L) with $\mathrm{Eu}(\mathrm{III})(\mathrm{M})$ in ethanol for different $\mathrm{M} / \mathrm{L}$ ratios.

\subsection{Permanent magnets}

\subsubsection{Extraction Experiments}

Taking into account the performances and the potential of CR4-DODGA for the extraction of REEs, we then studied the efficiency and the selectivity of this system for $\mathrm{Nd}$, Dy over Fe and B contained in a simulated leaching solution of permanent magnets. A new set of experiments was performed at $5 \mathrm{M}$ nitric acid with a total concentration of the metals fixed at $2 \mathrm{mM}$.

The concentration of the CR4-DODGA was varied from 1-3 mM, therefore the $C_{L} / C_{M}$ ratios varied from 0.5 to 1.5 . The data are presented in Table 4.

The results show that the ligand extracts, mostly $\mathrm{Nd}(\mathrm{III})$ and $\mathrm{Dy}(\mathrm{III})$, a negligible amount of $\mathrm{B}$, and no extraction was observed with respect to Fe. This suggests that CR4-DODGA is an appropriate extractant for the recovery of REE from permanent magnets. As predicted from the previous study, the ligand was more selective toward the HREE, (Dy(III)), with a selectivity factor of Dy over Nd equals about 11.77. The presenting results demonstrate the potential of CR4-DODGA toward the selective extraction of REE in regards to competitive ions especially iron, $\mathrm{SF}_{(\mathrm{Dy} / \mathrm{Fe})}>1600$, which is the main competitive ion in the nitric acid leaching solution. 
Table 4: Distribution value of Nd/Dy/Fe/B cations at $25^{\circ} \mathrm{C}$. Org. phase: $1-3 \mathrm{mmol} / \mathrm{L}$ CR4-DODGA in $90 \%$ toluene/10\% iso-octanol (v/v); Aq. phase: $2 \mathrm{mmol} / \mathrm{L}$ of cations in $5 \mathrm{~mol} / \mathrm{L} \mathrm{HNO}{ }_{3}$

\begin{tabular}{cccccccc}
\hline [Lig.] & $D(F e)$ & $D(D y)$ & $D(N d)$ & $D(B)$ & $S F(D y / N d)$ & $S F(D y / B)$ & $S F(N d / B)$ \\
\hline 1 & $<0.01$ & 2.52 & 0.52 & 0.03 & 4.85 & 88.12 & 18.18 \\
2 & $<0.01$ & 8.36 & 0.92 & 0.06 & 9.12 & 140.38 & 15.38 \\
3 & $<0.01$ & 16.29 & 1.38 & 0.06 & 11.77 & 293.95 & 24.97 \\
\hline
\end{tabular}

[Lig.] Ligand in $\mathrm{mM},[\mathrm{M}]_{\mathrm{t}}=2 \mathrm{mM}, 70 \% \mathrm{Fe}, 10 \% \mathrm{Dy}, 10 \% \mathrm{Nd}, 10 \% \mathrm{~B}$.

\subsubsection{Stripping and recovery of REEs}

After the extraction step the loaded organic solution contains about $94( \pm 2) \%$ of Dy and $56( \pm 6) \%$ of Nd initially present in the acid solution. Back-extraction experiments were implemented to strip quantitatively the Dy or the Dy and Nd from the organic phase using ammonium carbonate, ammonium oxalate and di-ionized water. Among the three tested solutions, ammonium carbonate and ammonium oxalate display promising results when the stripping was performed with an aqueous over organic phase ratio $\mathrm{A} / \mathrm{O}=2$. As shown in Table 5, Dy and $\mathrm{Nd}$ can be mainly recovered after stripping the organic phase with the ammonium carbonate or ammonium oxalate. Despite the lower value obtained for the stripping using water an interesting point is that the selective back-extraction of $\mathrm{Nd}$ should be considered. By increasing the ratio $\mathrm{A} / \mathrm{O}$ or perform successive stripping step the totality of the REEs extracted should be recovered mutually or separated as a function of the solution used.

Table 5: Recovery of REEs from an organic phase (3mM CR4-DODGA) by aqueous solution (ratio aqueous over organic phase $A / O=2$ ).

\begin{tabular}{ccc}
\hline Stripping solution & Dy recovery (\%) & Nd recovery (\%) \\
\hline $\mathrm{H}_{2} \mathrm{O}$ & 3 & 25 \\
{$\left[(\mathrm{NH} 4)_{2} \mathrm{CO}_{3}\right](\mathrm{mol} / \mathrm{L})$} & 53 & 51 \\
{$\left[(\mathrm{NH} 4)_{2} \mathrm{C}_{2} \mathrm{O}_{4}\right](\mathrm{mol} / \mathrm{L})$} & 52 & 54 \\
\hline
\end{tabular}

\section{Conclusions}

In line with our previous work, a ligand CR4-DODGA corresponding to a C-methyl-Calix(4)methylresorcinarene functionalized at the upper rim with four DGA binding units containing n-octyl groups was synthesized with satisfactory yield of $50 \%$. Rare earth (REES) can be extracted effectively with CR4-DODGA in a mixture of toluene/10\% iso-octanol ( $\mathrm{v} / \mathrm{v}$ ) as diluents from a simulated solution of permanent magnets. The ligand was investigated also toward a mixture of three lanthanides, $\mathrm{La}(\mathrm{III}), \mathrm{Eu}(\mathrm{III}), \mathrm{and} \mathrm{Yb}(\mathrm{III})$ at a 1:3 metal to ligand ratio, it was able to extract about $94 \%$ of $\mathrm{Yb} 52 \%$ of Eu and $15 \%$ of La. The distribution coefficients and selectivity factors increased with the increase of nitric acid concentration. An extraction mechanism was proposed from slope analysis and thermodynamic studies highlighting the differences between LREEs and HREEs which are linked to the efficiency of extraction. Further studies toward the applications of this CR4-DODGA are in progress.

\section{Experimental}

\subsection{General considerations}

Chemicals (analytically pure) were purchased from Sigma-Aldrich or Alfa Aesar and were used without further purification. Anhydrous solvents were purchased from Acros (AcroSeal ${ }^{\circledR}$ ). Adapted literature procedures were used for the synthesis of the cavitand I 25,26 and DODGA ${ }^{27}$. Reactions were monitored by thin layer chromatography (Merck TLC Silica Gel 60 F254).

Flash chromatography was performed using a combiflash Agilent Intelliflash 971-FP. NMR analyses were performed on a Bruker 400 ultrashield VS spectrometer. Displacements are reported in ppm using the solvent $\left(\mathrm{CDCl}_{3}: 7.26 \mathrm{ppm}{ }^{1} \mathrm{H} ; 77.16 \mathrm{ppm}{ }^{13} \mathrm{C}\right)$ as an internal reference. Metal concentrations were determined using a spectro ARCOS ICPAES spectrometer. Fourier transform infrared (FTIR) measurements were performed on Perkin Elmer Spectrum 100 instrument in ATR (Attenuated Total Reflection) mode. The wavenumber range was from $400 \mathrm{~cm}^{-1}$ to $4000 \mathrm{~cm}^{-1}$. The beam resolution was $4 \mathrm{~cm}^{-1}$. Background acquisition was done before measurement.

UV-vis absorption spectra of the ligand were collected on a single beam Cary 100 Bio spectrophotometer.

Melting points measurements were performed on a Buchi Melting Point M-560 apparatus. Melting points are uncorrected. 
Elemental analysis was performed using an ElementarVario Micro Cube apparatus ( $\mathrm{C}, \mathrm{H}, \mathrm{N}$ combustion analysis).

Mass spectrometry measurements were recorded in positive ionization mode using a Bruker micrOTOF-QII equipped with an electrospray ionization source and a time-of-flight analyzer.

\subsection{Syntheses}

Cavitand II: $0.2 \mathrm{~g}$ of cavitand I $(0.208 \mathrm{mmol})$ are poured into $1 \mathrm{~mL}$ of hexyl amine $(0.8427 \mathrm{~g}, 8.334 \mathrm{mmol})$, the obtained solution was stirred for 30 minutes at room temperature, then the excess hexyl amine was removed under reduced pressure to afford the compound II as brown crystals with a quantitative yield; $\mathrm{mp} 72-74^{\circ} \mathrm{C}$.

${ }^{1} \mathrm{H} \mathrm{NMR}\left(400 \mathrm{MHz}, \mathrm{CDCl}_{3}\right) \delta[\mathrm{ppm}]: 0.89\left(\mathrm{t}, 12 \mathrm{H}, \mathrm{J}=6.4 \mathrm{~Hz}, \mathrm{CH}_{2}-\mathrm{CH}_{3}\right), 1.296\left(\mathrm{~m}, 24 \mathrm{H},-\mathrm{CH}_{2}-\mathrm{CH}_{2}-\mathrm{CH}_{3}\right), 1.45\left(\mathrm{p}, 8 \mathrm{H}, \mathrm{J}=7.2 \mathrm{~Hz}, \mathrm{NH}-\mathrm{CH}_{2}-\right.$ $\left.\mathrm{CH}_{2}\right), 1.765\left(\mathrm{~d}, 12 \mathrm{H}, \mathrm{J}=7.2 \mathrm{~Hz}, \mathrm{CHCH}_{3}\right), 2.575\left(\mathrm{t}, 8 \mathrm{H}, 7.2 \mathrm{~Hz}, \mathrm{NH}-\mathrm{CH}_{2}-\mathrm{CH}_{2}\right), 3.58\left(\mathrm{~s}, 8 \mathrm{H}, \mathrm{Ar}-\mathrm{CH}_{2}-\mathrm{N}\right), 4.35(\mathrm{~d}, 4 \mathrm{H}, \mathrm{J}=6.8 \mathrm{~Hz}, \mathrm{inner}$ $\mathrm{OCH}_{2} \mathrm{O}$ ), $5.02\left(\mathrm{q}, 4 \mathrm{H}, \mathrm{J}=7.4 \mathrm{~Hz}, \mathrm{CH}-\mathrm{CH}_{3}\right), 5.9\left(\mathrm{~d}, 4 \mathrm{H}, \mathrm{J}=6.8 \mathrm{~Hz}\right.$, outer $\left.\mathrm{OCH}_{2} \mathrm{O}\right), 7.2(\mathrm{~s}, 4 \mathrm{H}, \mathrm{ArH}) .{ }^{13} \mathrm{C} \mathrm{NMR}\left(400 M H z, \mathrm{CDCl}_{3}\right) \delta[p p m]$ : 13.9, 16, 22.5, 26.8, 29.8, 43.1, 49.5, 99.2, 118.6, 126, 138.7, and 153.

Anal. Calcd (\%) for $\mathrm{C}_{64} \mathrm{H}_{92} \mathrm{~N}_{4} \mathrm{O}_{8}: \mathrm{C}, 73.53 ; \mathrm{H}, 8.87 ; \mathrm{N}, 5.36 ; \mathrm{O}, 12.24$. Found: $\mathrm{C}, 73.61 ; \mathrm{H}, 8.92 ; \mathrm{N}, 5.24$.

$\mathrm{ESI}(\mathrm{m} / \mathrm{z}): 1045.66[\mathrm{M}+\mathrm{H}]^{+}$.

Cavitand III: $0.376 \mathrm{~g}$ of 2-(2-(dioctylamino)-2-oxoethoxy) acetic acid DODGA (1.0529 mmol) and $0.142 \mathrm{~g}$ of hydroxybenzotriazole HOBt $(1.053 \mathrm{mmol})$ are poured into $30 \mathrm{ml}$ chloroform at $0^{\circ} \mathrm{C}$. The obtained suspension is stirred for 30 minutes at room temperature, after which $0.25 \mathrm{~g}$ of cavitand II $(0.239 \mathrm{mmol})$ and $0.217 \mathrm{~g}$ of dicyclohexylcarbodiimide DCC ( $1.053 \mathrm{mmol})$ are added and the resulting suspension is stirred for two days then the precipitates are removed by filtration and the solvent is evaporated. The obtained crude product is purified through a silica gel column chromatography using as eluent (dichloromethane/ methanol $5 \%$ ), to afford the pure cavitand III as a brown crystals (yield $50 \%$ ); $\mathrm{mp} 175-178^{\circ} \mathrm{C}$.

${ }^{1} \mathrm{H}$-NMR spectrum of cavitands III is in accordance with cone conformations such as cavitand I and II and is characterized by an AB pattern for bridging $\mathrm{O}-\mathrm{CH}_{2}-\mathrm{O}$ groups.

${ }^{1} \mathrm{H}$ NMR (400MHz, CDCl 3 ) $\delta$ [ppm]: 0.81 (b, 36H, CH $\left.\mathrm{CH}_{2}-\mathrm{CH}_{3}\right), 1.20\left(\mathrm{~b}, 104 \mathrm{H},-\mathrm{CH}_{2}-\mathrm{CH}_{2}-\mathrm{CH}_{3}\right), 1.46\left(\mathrm{~b}, 24 \mathrm{H}, \mathrm{NH}-\mathrm{CH}_{2}-\mathrm{CH}_{2}\right), 1.69(\mathrm{~b}, 12 \mathrm{H}$, $\mathrm{CHCH}_{3}$ ) , 2.99 (b, 8H, N-CH2-pentyl), 3.12 (b, 8H, N-CHz-heptyl), 3.23 (b, 8H, N-CH -heptyl), 4.26 ( bs, Ar- $\mathrm{CH}_{2}-\mathrm{N}$ and $16 \mathrm{H}, \mathrm{CO}-\mathrm{CH}_{2}-\mathrm{O}-$ $\left.\mathrm{CH}_{2}-\mathrm{CO}\right), 4.34\left(\mathrm{~b}, 4 \mathrm{H}\right.$, inner $\left.\mathrm{OCH}_{2} \mathrm{O}\right), 4.88\left(\mathrm{~b}, 4 \mathrm{H} \mathrm{CH}-\mathrm{CH}_{3}\right), 5.82\left(\mathrm{~b}, 4 \mathrm{H}\right.$, outer $\left.\mathrm{OCH}_{2} \mathrm{O}\right), 7.2(\mathrm{bs}, 4 \mathrm{H}, \mathrm{ArH})$.

${ }^{13} \mathrm{C} \mathrm{NMR}\left(400 \mathrm{MHz}, \mathrm{CDCl}_{3}\right) \delta[\mathrm{ppm}]: 13.9,14 ., 16.2,22.49,22.56,26.4,26.8,27 ., 27.6,28,28.9,29.15,29.22,29.26,31.11,31.4$, $31.74,31.75,38.2,45.9,46.9,68.8,69.1,99.4,119.2,122.36,138.56,153.68,168.34$.

Anal. Calcd (\%) for $\mathrm{C}_{144} \mathrm{H}_{240} \mathrm{~N}_{8} \mathrm{O}_{20} \mathrm{C}, 71.96 ; \mathrm{H}, 10.07 ; \mathrm{N}, 4.66 ; \mathrm{O}, 13.31$. Found: $\mathrm{C}, 72.08 ; \mathrm{H}, 10.18 ; \mathrm{N}, 4.54$.

HRMS ESI ( $\mathrm{m} / \mathrm{z}): 2426[\mathrm{M}+\mathrm{Na}]^{+}$, and $1202[\mathrm{M}+2 \mathrm{H}]^{2+} / 2$ (see Figure $\mathrm{S} 1$ in the supporting information)

\subsection{Solvent extraction procedure}

Rare earth element (REE) stock solutions were prepared at the desired acidity from $10000 \mathrm{mg} \cdot \mathrm{L}^{-1}$ ICP standard (in $1 \% \mathrm{HNO}_{3}$ ) of lanthanum, europium and ytterbium. A synthetic solution mimicking the leaching of magnet was prepared from $1000 \mathrm{mg} . \mathrm{L}^{-1} \mathrm{ICP}$ standard (in $1 \% \mathrm{HNO}_{3}$ ) of neodymium, dysprosium, iron and boron. The desired concentrations were prepared by dilution using ultrapure water (MilliQ, Millipore, $>18 \mathrm{M} \Omega \mathrm{cm}^{-1}$ ) and the acidity was adjusted with nitric acid.

Different organic solutions were prepared from CR4-DODGA at the specific concentration in a mixture of $10 \%$ iso-octanol/toluene. Iso-octanol was used as a phase modifier. Turbid solutions were obtained when solutions without the phase modifier were contacted with $>2 \mathrm{M}$ nitric acid.

Organic phases were pre-equilibrated with an aqueous phase at the same acidity as the extraction step without REE cations. The pre-equilibrated organic phases were then contacted with an equal volume of an aqueous acidic stock solution of REEs in a thermostated shaker (Infor-ht ${ }^{\circledR}$ ecotron) at $25^{\circ} \mathrm{C}$ and $400 \mathrm{rpm}$, it was ensured that equilibrium was reached within one hour. Phases were separated after centrifugation at $4000 \mathrm{rpm}$ for 30 minutes (sigma 3-16 PK). After centrifugation, the separated aqueous phases were subjected to ICP-AES analysis in order to determine the distribution ratio $\left(D_{M}\right)$, which is the ratio of the total concentration of metal $M$ in the organic phase to the total concentration of the same metal in the aqueous phase, i.e. $D_{M}=$ $\left[\mathrm{M}_{\mathrm{org}}\right] /\left[\mathrm{M}_{\mathrm{aq}}\right]$. The experiments were carried out in duplicate measurements with precision of $\pm 5 \%$.

The full set of solvent extraction data of lanthanide cations $\left(\mathrm{La}^{3+}, \mathrm{Eu}^{3+}\right.$, and $\left.\mathrm{Yb}^{3+}\right)$ are summarized in Table 1, Table S1 and Table S2 (see supporting information).

\subsection{Back-extraction Experiments}

The loaded organic phase was stripped with a solutions of ammonium carbonate, ammonium oxalate (typically $0.5 \mathrm{M}$ ) or pure water (MilliQ). Back-extractions were performed at room temperature $(22-24 \circ \mathrm{C}$ ) by contacting equal or various volumes of organic and aqueous phase during 1 hour (ratio aqueous over organic phase $A / O=1$ or 2 ). After separation by centrifugation (4000 rpm for $10 \mathrm{~min}$ ), metals concentrations were measured in the aqueous phase by ICP/AES.

\subsection{IR Spectrophotometric titration}

Spectrophotometric titrations of Ligand III with Eu were performed in a small vial. $0.2 \mathrm{ml}$ of ligand solution in ethanol of concentration $25 \mathrm{mM}$ was added into the cuvette, to which another solution of europium nitrate pentahydrate, $\mathrm{Eu}\left(\mathrm{NO}_{3}\right)_{3} .5 \mathrm{H}_{2} \mathrm{O}$ in ethanol of concentration $50 \mathrm{mM}$ was added in order to change the ratio between the metal and the ligand $\left(C_{M} / C_{L}\right)$. After each 
addition the solution was mixed for $10 \mathrm{~min}$ and three drops of the resulting solution were taken and deposited on the crystal of the IR instrument, the ethanol was left to evaporate before each measurement.

\subsection{UV Spectrophotometric titration}

Spectrophotometric titrations of Ligand III with Eu were collected in the wavelength region $220-340 \mathrm{~nm}(0.1 \mathrm{~nm}$ interval). The titrations were performed by following the ligand in ethanol $(25 \mathrm{mM})$ after the addition of the appropriate amount of the europium nitrate pentahydrate, $\mathrm{Eu}\left(\mathrm{NO}_{3}\right)_{3} .5 \mathrm{H}_{2} \mathrm{O}$ solution $(50 \mathrm{mM}$ in ethanol). After each addition the solution was mixed for $10 \mathrm{~min}$ before the spectrum was recoded.

\section{Acknowledgements}

We would like express our appreciation to Christian Duchamp for mass spectrometry analysis.

We gratefully acknowledge the financial support for this project by the Lebanese University, CEDRE program, CNRSL (the National Council for Scientific Research, Lebanon), French CNRS, Montpellier University and the Labex Project CheMISyst (ANR-10-LABX-0501).

\section{References}

1 V. K. Manchanda and P. N. Pathak, Sep. Purif. Technol., 2004, 35, 85-103.

J. N. Mathur, M. S. Murali and K. L. Nash, Solvent Extr. Ion Exch., 2001, 19, 357-390.

3 A. P. Paiva and P. Malik, J. Radioanal. Nucl. Chem., 2004, 261, 485-496.

4 M. P. Jensen, R. Chiarizia, J. S. Ulicki, B. D. Spindler, D. J. Murphy, M. M. Hossain, A. Roca-Sabio, A. de Blas and T. Rodriguez-Blas, Solvent Extr. Ion Exch., 2015, 33, 329-345.

5 H. H. Dam, D. N. Reinhoudt and W. Verboom, Chem. Soc. Rev., 2007, 36, 367-377.

6 Z. Kolarik, Chem. Rev., 2008, 108, 4208-4252.

7 S. A. Ansari, P. Pathak, P. K. Mohapatra and V. K. Manchanda, Sep. Purif. Rev., 2011, 40, 43-76.

8 H. Huang, S. Ding, N. Liu, Y. Wu, D. Su and S. Huang, Sep. Purif. Technol., 2014, 123, 235-240.

9 H. Stephan, K. Gloe, J. Beger and P. Muhl, Solvent Extr. Ion Exch., 1991, 9, 459-469.

10 Y. I. Sasaki and G. R. Choppin, Anal. Sci., 1996, 12, 225-230.

11 H. Narita, T. Yaita and S. Tachimori, Solvent Extr. Ion Exch., 2004, 22, 135-145.

12 M. Iqbal, P. K. Mohapatra, S. A. Ansari, J. Huskens and W. Verboom, Tetrahedron, 2012, 68, 7840-7847.

13 S. A. Ansari, P. Pathak, P. K. Mohapatra and V. K. Manchanda, Chem. Rev., 2012, 112, 1751-1772.

14 M. M. Garcia, R. T. Cabanas, A. T. Ochoa, A. Toscano and R. Cruz-Almanza, Fullerene Sci. Technol., 2000, 8, 475-482.

15 F. C. Tucci, A. R. Renslo, D. M. Rudkevich and J. Rebek, Angew. Chem., Int. Ed., 2000, 39, 1076-1079.

16 K. Yonetake, T. Nakayama and M. Ueda, J. Mater. Chem., 2001, 11, 761-767.

17 O. Haba, K. Haga, M. Ueda, O. Morikawa and H. Konishi, Chem. Mater., 1999, 11, 427-432.

18 C. Chamseddin and T. Jira, Chromatographia, 2014, 77, 1167-1183.

19 K. Kobayashi and M. Yamanaka, Chem. Soc. Rev., 2015, 44, 449-466.

20 F. Davis, C. F. J. Faul and S. P. J. Higson, Soft Matter, 2009, 5, 2746-2751.

21 B. A. Makwana, D. J. Vyas, K. D. Bhatt, V. K. Jain and Y. K. Agrawal, Spectrochim. Acta, Part A, 2015, 134, 73-80.

22 H. Boerrigter, W. Verboom and D. N. Reinhoudt, J. Org. Chem., 1997, 62, 7148-7155.

23 H. Boerrigter, W. Verboom, F. de Jong and D. N. Reinhoudt, Radiochim. Acta, 1998, 81, 39-45.

24 M. Wehbie, G. Arrachart, I. Karamé, L. Ghannam, S. Pellet-Rostaing. Sep. Purif. Technol., 2016, 169, 17-24.

25 D. J. Cram, S. Karbach, H. E. Kim, C. B. Knobler, E. F. Maverick, J. L. Ericson and R. C. Helgeson, J. Am. Chem. Soc., 1988, 110, $2229-2237$.

26 J. R. Moran, S. Karbach and D. J. Cram, J. Am. Chem. Soc., 1982, 104, 5826-5828.

27 S. Taktak, R. Weissleder and L. Josephson, Langmuir, 2008, 24, 7596-7598.

28 R. G. Pearson, J. Chem. Educ., 1968, 45, 581-586

29 K. L. Nash, Solvent Extr. Ion Exch., 1993, 11, 729-768.

30 S. A. Ansari, P. K. Mohapatra, S. M. Ali, A. Sengupta, A. Bhattacharyya and W. Verboom, Dalton Trans., 2016, 45, 5425-5429.

31 S. Andersson, K. Eberhardt, C. Ekberg, J. O. Liljenzin, M. Nilsson and G. Skarnemark, Radiochim. Acta, 2006, 94, 469-474.

32 S. A. Ansari, P. N. Pathak, M. Husain, A. K. Prasad, V. S. Parmar and V. K. Manchanda, Radiochim. Acta, 2006, 94, $307-312$. 